\title{
Free Situation Judgement Test e-learning course
}

The Dental Defence Union (DDU) has launched its online DF1Success course to support student dental members taking the Situation Judgement Test (SJT) this November. This free, one-hour e-learning course is designed to offer practical interactive support to final year students, helping to boost their confidence with taking the SJT. It provides sample SJT questions and expert advice from the DDU's dento-legal advisers on how to apply dento-legal principles to the SJT.

Areas covered in the DF1Success course include:

- What qualities the SJT is looking for

- Practical tips on taking the test

- Analysing sample SJT questions.
Although the SJT has previously been part of the selection process for foundation training, it is even more important this year, as due to the coronavirus pandemic, applications will be ranked based on the SJT score alone.

Upon completing the course, not only will members have had experience of answering situational judgement questions but also an understanding of how to apply dento-legal principles to a range of professional situations.

For more information about the DF1Success course, visit https://www.theddu.com/learnand-develop/course-listing/ sjt-preparation-for-df1-success.

\section{Quality, cost-efficiency and maximum infection control}

For top quality combined with unbeatable cost-efficiency and ergonomics, discover the Synea Vision and Synea Fusion dental turbines from W\&H.

To support infection control compliance, all W\&H handpieces can be disinfected in a thermo washer and are sterilisable. In addition, they all include the patented hygienic head feature with an anti-retraction system to minimise aerosol production, which is particularly relevant given the current circumstances in dentistry.

Plus, like all solutions from $\mathrm{W} \& \mathrm{H}$, they are accompanied by the expert customer support that the team is so well known for across the dental profession.
To find out more visit www.wh.com/ en_uk, call 01727874990 or email office.uk@ wh.com.

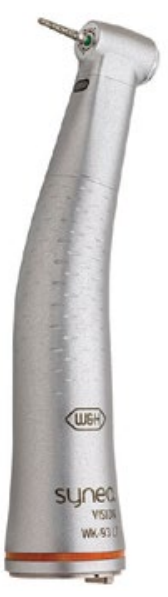

\section{Seeing the bigger picture}

Henry Schein Dental has recently published a Magnification e-book everything you need to know about loupes, lights and microscopes - all online in one place!

Being able to see the oral cavity in full focus is vital for diagnostics and treatment, which is why loupes, lights and microscopes are some of the most important tools in the dental professional's armoury. But which treatments are best-suited for magnification and how do you choose the magnification tools that are right for you?

Henry Schein Dental's

Magnification e-book has the answers. This new interactive guide takes an in-depth look into loupes, lights and microscopes and the different options available. Discover the advantages and applications and what you should consider in order to make an informed choice.

There's never been a better time to invest in magnification and Henry Schein Dental offers the best equipment and expert advice to help dental professionals make the most appropriate choice for their clinical needs.

Download the e-book at http://hsdmagnification.co.uk/ or to speak to a magnification specialist or request a demonstration, call 08000284870 or emailinfo@henryschein.co.uk.

\section{Be as financially prepared as possible to enhance your chances of success}

Recovering from the last few months could be a long journey for some dental practices in the UK. Make sure you are as financially prepared as possible to enhance your chances of short- and longterm success.

By working with the highly experienced IFAs from money4dentists, you can reassess your current situation and put arrangements in place to protect the future of your business. Whether that involves better utilising tax relief opportunities or making the most of the Bounce Back Loan Scheme (BBLS) currently available from the government, the experts can guide you through all the paperwork for maximum benefit.

They can also offer support in other areas such as streamlining your expenses, minimising inefficiencies or renegotiating contracts with suppliers.

Make sure your practice is financially prepared to recover as fully and as quickly as possible from the COVID-19 pandemic.

For more information call 0845345 5060 or 0754DENTIST. Email info@ money4dentists.com or visit www.money4dentists.com.

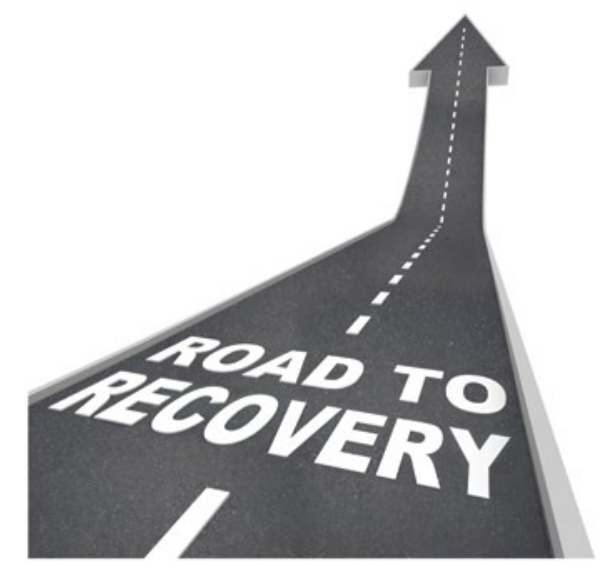

